of early childhood malnutrition. Because of their early insight, Stoch and Smythe have recently been able to report the end of their prospective study ${ }^{7}$ of malnourished and comparison groups of children over 15 years. Hoorweg and Stanfield, ${ }^{8}$ through the continual careful recording of an almost equal number of years by the Medical Research Council Nutrition Unit in Kampala, have been able to compare retrospectively in their teens two groups of children who were malnourished and non-malnourished in the first and second years of their lives. Both studies came to the same conclusion: the malnutrition syndrome casts its shadow recognisably into the late teens.

Stoch and Smythe failed to show, however, that the initial episode of malnutrition was the sole cause of the disparity of performance in their two groups. At the outset these groups were separated from one another by additional educational and social differences. Furthermore, both the lowered capacity of the malnourished children and the disparity in their head circumference persisted despite some improvement in their environment, care, and education. The imponderable effects of continuing depressing and depriving influences on the two groups of children were underlined by the fact that even the control children were well below the élite in both growth and development, particularly the girls. Stoch and Smythe accept that they have been observing not only the effects of early severe malnutrition but also those of longer-term, less definite malnutrition-with all that term implies in social, intellectual, and motivational deprivation.

Hoorweg and Stanfield's analysis of carefully controlled groups, albeit from retrospective data, came to a firmer conclusion: the chronic undernutrition component was responsible for the deficit rather than any acute malnutrition which might punctuate or terminate it. They concluded that the intellectual abilities of children who suffer from a long period of chronic undernutrition but who never experience an acute episode are likely to suffer similar impairment.

This leads to two final questions. Is it ever possible to help a child catch up to his full potential ? What happens if adequate and comprehensive rehabilitation is given over the whole period between early childhood malnutrition and adult life? No human studies have yet pointed to a critical period after birth, as has been found in animals. Complete catch-up in growth in both height and weight has been seen when the malnutrition of coeliac disease is treated with adequate rehabilitation. ${ }^{9}$ Graham and Adrianzen ${ }^{10}$ showed the potential that chronic malnourished and deprived children have in catching up in growth in later childhood through adequate fostering. Two studies ${ }^{11} 12$ have shown no difference in comparisons between previously malnourished and non-malnourished children after long intervals. Yet this may be a false impression: the controls may have been chronically undernourished while escaping a period of acute malnutrition-which may not result in permanent effects anyway. Most studies do in fact show that the "control" children do less well than their élite well-nourished compatriots.

Such speculation begs the question of what is complete and continuous rehabilitation. Hansen has claimed that even severely malnourished children can be restored to their full potential. ${ }^{13}$ In practical terms, however, failing complete prevention, infant and childhood undernutrition will continue to need to be detected and remedied. Children with established malnutrition need rehabilitation as completely, comprehensively, and continuously as possible. The effort will be great, but the reward even greater by far-in avoiding the ultimate cost of diminished potential and the cycle, repeated from generation to generation, of stunting of both stature and intellect.

1 Schrimshaw, N S, and Gordon, J E, eds, Malnutrition, Learning and Behaviour, p 289. Cambridge, Mass, MIT Press, 1968.

${ }^{2}$ Nutrition, the Nervous System and Behaviour, Scientific Publication No 251. Washington, Pan American Health Organisation, 1972.

${ }^{3}$ Winick, M, Malnutrition and Brain Development. New York, Oxford University Press, 1976.

4 Dobbing, J, in Scientific Foundations of Paediatrics, eds J A Davis and J Dobbing, p 565. London, Heinemann, 1974.

${ }^{5}$ Richardson, S A, Birch, H G, and Hertzig, M E, American fournal of Mental Deficiency, 1973, 77, 623.

${ }^{6}$ Dobbing, J, Lancet, 1974, 1, 802.

7 Stoch, M B, and Smythe, P M, Archives of Disease in Childhood, 1976, 51, 327.

${ }^{8}$ Hoorweg, J, and Stanfield, J P, Developmental Medicine and Child Neurology, 1976, 18, 330.

9 Barr, D G D, Schmerling, D H, and Prader, A, Pediatric Research, 1972, 6, 521.

${ }^{10}$ Graham, G G, and Adrianzen, T B, Fohns Hopkins Medical fournal, 1972, 131, 204.

11 Evans, D E, Moodie, A D, and Hansen, J D L, South African Medical fournal, 1971, 45, 1413.

12 Ghai, O P, et al, Indian Paediatrics, 1973, 10, 155.

13 Hansen, J D L, personal communication, 1976.

\section{Endocrine disturbances in chronic hepatic disease}

Endocrine function is often disturbed in men with chronic liver failure. The major clinical features-testicular atrophy, reduced potency and fertility, and gynaecomastia- have been recognised for many years. ${ }^{1}$ There is also a lower incidence of benign prostatic hypertrophy in chronic liver disease. ${ }^{2} 3$ Endocrine changes in women are less familiar: hepatic cirrhosis is less frequent and most patients are postmenopausal. Nevertheless, the recent development of sensitive and specific assays for the sex steroids, sex steroid binding globulin (SSBG), and the gonadotrophins has stimulated interest in the hormonal disturbances in these patients.

The clinical signs of endocrine disturbance in liver disease have usually been attributed to "hormonal imbalance," with oestrogen excess, said to result from reduced metabolic clearance, as the primary abnormality. The plasma concentrations of oestradiol have been reported as raised ${ }^{45}$ or normal. ${ }^{6}$ ? A recent large study with results from 117 patients showed that total plasma oestradiol concentrations were significantly higher than in the normal population, though $51 \%$ of values fell within the normal range. ${ }^{8}$ There was also a small, but significant, increase in free oestradiol concentration, though the values were widely scattered. Detailed metabolic studies failed to show any reduction in the metabolic clearance rate or in the plasma production rate of oestradiol, but the peripheral conversion of testosterone to oestradiol was increased. About half the circulating oestradiol in normal men, is derived from the peripheral conversion of testosterone ${ }^{y}$ while the remainder is secreted by the testes. ${ }^{10}$ This increase in the proportion of testosterone converted to oestradiol peripherally is offset by a reduction in the production of testosterone. These recent observations suggest that the traditional view, that a reduced metabolic clearance of oestrogen is the primary abnormality, is no longer tenable.

Low or normal total testosterone values have been reported in cirrhotic patients. ${ }^{11-13}$ There is, however, general agreement that there the free (biologically active) testosterone concentration is reduced. ${ }^{7814}$ Baker et $a l^{8}$ have also shown that there is a 
reduction in its production and metabolic clearance rates. Planar 17- $\beta$-hydroxysteroids such as oestradiol and testosterone are transported in the plasma by SSBG. The concentration of SSBG is increased in patients with high circulating oestrogen concentrations. ${ }^{1516}$ Nevertheless, only the free (non-proteinbound) steroid in the circulation is biologically activewhich explains the observation by Vermeulen et $a l^{17}$ that an increase in SSBG capacity is associated with a reduced metabolic clearance rate for testosterone. SSBG capacity is much increased in men with liver disease. ${ }^{78}$

Two recent studies ${ }^{814}$ have attempted to assess the importance of these changes in sex steroid concentrations by measuring luteinising hormone ( $\mathrm{LH})$ and follicle stimulating hormone (FSH) basally and after stimulation with the gonadotrophin releasing hormone (LH/FSH-RH) and clomiphene. Basal LH and FSH levels were normal in most patients and raised in most of the rest. The lowest gonadotrophin concentrations were found in those with the most advanced liver failure and (as might be expected) one study ${ }^{8}$ showed an inverse correlation between $\mathrm{LH}$ and testosterone concentrations. There were variable responses to $\mathrm{LH} / \mathrm{FSH}-\mathrm{RH}$ : normal in most patients but suppressed in severe hepatic failure or exaggerated if gynaecomastia was present. Clomiphene was given to only five patients by Baker et $a l^{8}$ and variable responses were observed, so that no firm conclusions could be drawn. Human chorionic gonadotrophin (HCG) stimulated an increase in plasma testosterone concentration in most cirrhotic patients, though the response was substantially less than in normal controls or in patients with pituitary failure.

These recent observations show how much variation there may be among published reports; furthermore, a wide range of endocrine and biochemical abnormalities may be seen within a single study. Clearly technical difficulties and patient selection may play some part in accounting for these differences, and the data are in any case derived from patients with cirrhosis and liver failure of varying duration and severity. The cause and nature of the liver failure may also be relevant. Endocrine signs seem more prevalent in alcoholic cirrhosis ${ }^{7818}$; this may represent more severe disease in this group but a specific association with alcohol cannot be excluded. Pituitary failure may occur in haemochromatosis, ${ }^{19} 21$ and other factors such as age and drug treatment (particularly spironolactone, which may cause gynaecomastia and impotence ${ }^{22}$ ) may also account for some of the differences.

No single hypothesis will account for all the endocrine features of chronic liver disease, and probably any attempt to do so is unrealistic. Current data cast doubt on the view that the primary abnormality is a reduced clearance of oestrogens. The high circulating oestrogen concentrations found in some patients may result from increased conversion of testosterone to oestradiol, and other androgen-to-oestrogen conversions may also be increased in cirrhosis (for instance, testosterone $\rightarrow$ androstenedione $\rightarrow$ oestrone ${ }^{23}{ }^{24}$ ), but in many patients these conversions are balanced by a reduction in testosterone production. Why oestrogen concentrations are raised remains uncertain, but if it is the primary abnormality the increase in SSBG and decrease in total and free testosterone are then readily explained. The alternative hypothesis is that there is some primary hypogonadism with a reduction in testosterone production, increased peripheral conversion to oestrogens, and a secondary increase in gonadotrophin concentrations in some patients. Similar observations have been made in some men with chronic renal failure, and possibly these changes may accompany many chronic illnesses. The possible role of inadequate gonadotrophic stimulation of the testes (even after excluding those patients with haemochromatosis) is uncertain. The inverse relation between testosterone and $\mathrm{LH}^{8}$ suggests that the feedback mechanism is intact, though the observation that $\mathrm{LH}$ concentrations are normal in about $65 \%$ of patients and the free testosterone is reduced in about $90 \%$ suggests that the sensitivity of the control system has been reset. Possibly the increase in oestrogen may be responsible.

The results of studies with the new assay techniques have posed many new problems. Probably no clear answers will emerge until more attention is given to the nature of the primary disease, the duration of illness, and drug treatment. Further studies should also include more detailed examination of the possible role of other steroids with oestrogenic and androgenic properties; the factors which regulate peripheral steroid interconversions; and the part played by other hormones (such as prolactin).

${ }^{1}$ Lloyd, C W, and Williams, R H, American fournal of Medicine, 1948, 4, 315 .

${ }^{2}$ Bennett, H S, Baggenstoss, A H, and Butt, H R, American fournal of Clinical Pathology, 1950, 20, 814.

${ }^{3}$ Stumpf, H H, and Wilens, S L, Archives of Internal Medicine, 1953, 91, 304.

4 Korenman, S G, Perrin, L E, and McCallum, T, fournal of Clinical Investigation, 1969, 48, 45a.

5 Chopra, I J, Tulchinsky, D, and Greenaway, F L, Annals of Internal Medicine, 1973, 79, 198.

${ }^{6}$ Kent, J R, et al, Gastroenterology, 1973, 64, 111.

7 Galvo-Teles, A, et al, Lancet, 1, 173.

${ }^{8}$ Baker, H W G, et al, Quarterly fournal of Medicine, 1976, 45, 145.

${ }^{9}$ Longcope, C, Layne, D S, and Tait, J F, fournal of Clinical Investigation, 1968, 47, 93

${ }_{10}$ Kelch, R P, et al, fournal of Clinical Investigation, 1972, 51, 824.

11 Coppage, W S, and Cooner, A E, New England fournal of Medicine, 1965, 273, 902.

12 Baker, H W G, et al, Abstracts of the 4th International Congress of Endocrinology, No 327. Amsterdam, Excerpta Medica, 1972.

13 Vermeulen, A, Mussche, M, and Verdonck, L, Abstracts of the 4th International Congress of Endocrinology, No 305. Amsterdam, Excerpta Medica, 1972

14 Mowat, N A G, et al, Gut, 1976, 17, 345.

15 Burton, R M, and Westphal, U, Metabolism, 1972, 21, 253.

${ }_{16}$ Pearlman, W H, Crepy, E, and Murphy, M, fournal of Endocrinology and Metabolism, 1967, 27, 1012.

17 Vermeulen, A, et al, fournal of Clinical Endocrinology and Metabolism, 1969, 29, 1470.

18 Powell, L W, Mortimer, R, and Harris, D O, Medical fournal of Australia, $1971,1,941$.

19 Stocks, A E, and Martin, F I R, American fournal of Medicine, 1968, 45, 839.

20 Stocks, A E, and Powell, L W, Lancet, 1972, 2, 298.

21 Tourniaire, J, et al, fournal of Clinical Endocrinology and Metabolism, 1974, 38,1122 .

22 Clark, E, fournal of the American Medical Association, 1965, 193, 163.

${ }^{23}$ Thijssen, J H, Lourens, J, and Donker, G H, Acta Endocrinologica, 1971, suppl 155, 116

24 Thijssen, J H, Lourens, J, and Donker, G H, fournal of Endocrinology, 1973, 57, xlix.

\section{Student health}

For most students their arrival at university, polytechnic, or college is their first experience of life away from home. Suddenly, in the midst of a turmoil of new excitements and responsibilities, they find themselves cut off from the security and practical reassurance of their families. In these circumstances student health services can play an important part in providing a non-demanding source of help and advice as well as practical medical care. The caricature image limited to "sex and acne" has long since been outgrown, and-as with any subdivision of medicine-student physicians now have their own body of expertise. Some of this knowledge has been tapped for a short series of articles on student health, beginning this week at $\mathrm{p} 1177$. 